\title{
INTRAFIRM TECHNICAL KNOWLEDGE \\ AND COMPETITIVE ADVANTAGE: \\ A FRAMEWORK AND EXPLORATORY STUDY
}

\author{
Morry Ghingold \\ Bloomsburg University of Pennsylvania \\ Bloomsburg, PA \\ Ernest H. Hall, Jr. \\ University of Southern Indiana \\ Evansville, IN \\ Bruce Johnson \\ Xavier University \\ Cincinnati, $\mathbf{O H}$
}

\begin{abstract}
The ability of managers to monitor, acquire, and manage new technologies may be a critical resource in developing a sustainable competitive advantage (Barney, 1991). Expanding on recent work by Day (1994), this paper develops a conceptual framework that links intrafirm technical knowledge with the ability to develop and maintain a sustainable competitive advantage. Focusing on a sample of production/operation managers, a key industrial buying constituency, an exploratory study was undertaken that examined the linkage between managers' technical knowledge and their decision making styles and outcomes. Results of the present study suggest strong relationships among technical knowledge, decision making styles and outcomes. Based on these findings, it is argued that firms with managers who possess greater technical knowledge will be better equipped to develop and maintain a competitive advantage.
\end{abstract}

\section{Intrafirm Technical Knowledge and Competitive Advantage: A Framework and Exploratory Study}

Developing and sustaining a competitive advantage is the ultimate goal of strategic management (Barney, 1991; Perteraf, 1993). As the research on competitive advantage has progressed and become more focused, adding detail to its application, its usefulness and popularity have increased among both practitioners and academics (Barney, 1991; Day 1994; Wernerfelt, 1984). Based on the seminal work of Porter $(1980,1985)$, several strategies have been identified for developing a sustainable competitive advantage: cost leadership, differentiation, and focus. The imperative of pursuing one or more of these broad strategies to 
establish a competitive advantage is well understood and widely accepted among academics and practitioners alike (Day, 1994; Hill, 1988).

Given the firm grounding upon which competitive advantage has been built, research interest has shifted to prerequisite conditions, skills, resources, and capabilities, which enable a firm to achieve and sustain competitive advantage (Barney, 1991; Bartness \& Cerny, 1993; Day, 1994; Peteraf, 1993; Wernerfelt, 1984). Through the judicious and effective allocation of critical resources, a firm is able to concentrate on building and exploiting distinctive competencies, which can result in sustainable competitive advantage (Barney, 1991). However, such normative prescriptions are fairly broad and difficult for managers to apply.

Day (1994) has presented a synthesis of current research that integrates competitive advantage with the market-driven organization by providing a holistic perspective of competitive advantage and a conceptual framework that links internal resources, marketplace capabilities, and process factors as drivers of competitive advantage and superior firm performance. Day (1994) and other scholars contend that positions of competitive advantage result from market-wide distinctive capabilities (Amit \& Schoemaker, 1993; Peteraf, 1993). These broadly defined capabilities are partly based on firm specific competencies (Day 1994). According to Barney (1991) a firm's resources can be divided into three categories: physical (Williamson, 1975), human (Becker, 1964), and organizational (Tomer, 1987).

Of these three categories, the human resource will be singled out as a critical business resource and serve as the foundation for the present paper. First, the human component of an organization is the most unpredictable and unique, representing resources that are difficult to understand and replicate; two essential requirements for developing a sustainable competitive advantage (Barney, 1991). Second, due to the difficulties associated with measurement, the human resource issue has not been widely studied. Third, due to their richness and complexity, human resources may be the ultimate source of competitive advantage (LeonardBarton 1992; Mahoney \& Pandian, 1992).

Human resources include such items as: training, experience, judgment, intelligence, and insight of a firm's managers. Therefore, human resources at the business level can be understood as complex bundles of skills and knowledge that lead to superior asset utilization or customer service (Teece, Pisano \& Shuen, 1991). As Mahoney \& Pandian (1992) suggest, unique capabilities arising from technical know-how and managerial ability "are important sources of heterogeneity that may result in sustained competitive advantage" (p. 365).

Combining the richness of the human resource with research conducted on business-level strategy (Porter, 1980, 1985) and competitive advantage (Barney, 1991; Wernerfelt, 1984) provides a more complete picture of an organization's potential for success. Regardless of the strategy pursued the ability of managers, employees and others to implement the chosen strategy is essential to future success and may determine the firm's fate. 
Within this framework technical knowledge plays a major factor in driving business-level capabilities and competitive advantages (Leonard-Barton, 1992; Mahoney \& Pandian, 1992). This knowledge encompasses employee technical knowledge, training, and experience (Leonard-Barton 1992; Mahoney \& Pandian, 1992). Citing Penrose (1959), Mahoney \& Pandian argue that "A firm may achieve rents not because it has better resources, but rather the firm's distinctive competence involves making use of its resources" (1992: 365). One source of distinctive competence is technical knowledge, where efficiencies result from the application of knowledge to the processes of an organization.

Technical knowledge has continued to play an increasing role in modern business. The importance of understanding innovations within the areas of operations research and technology are clearly evidenced by programs such as Total Quality Management, process reengineering, and Just-In-Time management. Technical knowledge is defined as the knowledge, information, and expertise in applying and managing technology that directly impacts the operations processes of the organization (Ghingold \& Johnson, 1997).

Such a definition includes familiarity, understanding, and awareness of firm operations, including technologies used, product designs, equipment, production processes, operating facilities, and information systems (Porter, 1980). Any decision made with respect to business operations is defined as technical decision making. The interaction of technical knowledge and decision making with regard to technical aspects related to production processes is the primary focus of the current study. The present paper will develop and empirically test a theoretical framework that integrates technical knowledge, decision-making style, and outcomes. It is argued that these variables and their associated relationships have the capability to develop and maintain a competitive advantage based on intrafirm technical knowledge.

\section{The Role of Technology in Competitive Advantage}

Day \& Wensley (1988) define competitive advantage using a marketplace perspective. In their model, a firm's superiority in technological resources allows it to develop a position of advantage over its competitors. This position is achieved by offering customers the lowest delivered cost or superior customer value, paralleling Porter's (1985) business-level strategies of cost leadership, differentiation and focus. The firm's optimal use of current technologies relevant to its industry and markets has been noted by Porter $(1980,1985)$. The importance of technology and technical knowledge for firm success is implicit in both the Barney (1991) and Day \& Wensley (1988) frameworks. However, the specific role of technology management in these models has not been critically examined.

Day (1994) argues that technology management plays a direct role in establishing a competitive advantage. Day's classification of key capabilities distinguishes between capabilities that are externally and internally focused. Exter- 
nally focused capabilities are reflective of market-driven firms and are categorized by their outside-in activities (e.g., market sensing, developing linkages and relationships with customers, etc.). Internally focused firms emphasize internal capabilities that are deployed from the inside-out and are activated by market requirements (e.g., technology development, manufacturing processes, etc.). Within this framework technical knowledge enables a firm to respond to the market and thereby, create and sustain a competitive advantage. This elaboration on the role of technical knowledge in establishing a competitive advantage mirrors the findings in the operation management literature (Schmenner, 1983), which has long heralded the strategic importance of technology and technical knowledge (Hayes \& Wheelwright, 1984). Effective utilization of technology has been linked to the development of competitive advantages based on several criteria: (1) reduced costs (Henderson, 1982; Schmenner, 1983), (2) better quality (Hayes \& Wheelwright, 1984), (3) faster adoption of new process technologies (McFarlan, McKenney \& Pyburn, 1983; Raho, Belohlav \& Fiedler, 1987), or (4) more successful competition, particularly against global competitors (Nayak, 1984).

Thus, for both manufacturing and service organizations alike, effective utilization of technology should be a central part of competitive strategy. Many of the principal benefits of effective technology utilization (e.g., cost reductions, quality improvements, improvement in speed of new product developments, etc.) relate directly to the positions of competitive advantage defined by Porter (1985), and Day \& Wensley (1988) (i.e., cost and value leadership) and the concept of business capabilities (Day, 1994). The application of technical knowledge as a firm resource is also consistent with the resource-based view of the firm (Barney, 1991; Wernerfelt, 1984). It is upon this critical resource that the development of successful business-level strategies rests (Porter, 1980, 1985). Based on this discussion, we can conclude that the linkage between technical knowledge and competitive advantage is critical to a firm's future success.

\section{Managing Technical Knowledge and Competitive Advantage}

The strategic importance of effective technology utilization and management is well understood and widely accepted as a means for creating a sustainable competitive advantage (Barney, 1991; Becker, 1964; Mahoney \& Pandian, 1992; Porter, 1980, 1985). However, research efforts have begun to focus on understanding the conditions necessary for developing a competitive advantage (Bartness \& Cerny, 1993; Day \& Wensley, 1994; Peteraf, 1993). It has been argued by Ghingold \& Johnson (1997) that technical knowledge is "an important strategic asset of the firm that is essential for achieving and sustaining competitive advantage." The result of obtaining and sustaining a technical knowledge base provides the firm with the ability to exploit technological advances to the fullest and serves as the basis for determining how technology and technological change can best be managed. 
Figure 1 presents a general framework linking technical knowledge with competitive advantage at a macro level of analysis. As can be seen, the technical knowledge of management may serve as the foundation for developing a competitive advantage. It is suggested that the amount of technical knowledge possessed by management will influence decision style, decision outcome, technology-based competencies, and competitive advantage. All of these variables are contained within the organization, while external market-driven forces will interact in determining decision outcomes and the effectiveness of technology-based competencies. When incorporating technical knowledge and decision making in the context of manufacturing technology, the framework suggests the following relationships:

1. The level of technical knowledge among management will have an impact on the decision-making style(s) used.

2. The decision-making style(s) used by management will result in different outcomes.

3. Technology-related decision outcomes will affect the firm's ability to achieve specific technology-based competencies.

4. A firm's ability to develop distinctive competencies and leadership positions will determine its ability to achieve and sustain a competitive advantage.

\section{Figure 1 \\ A Macro Framework Linking Technical Knowledge and Competitive Advantage}

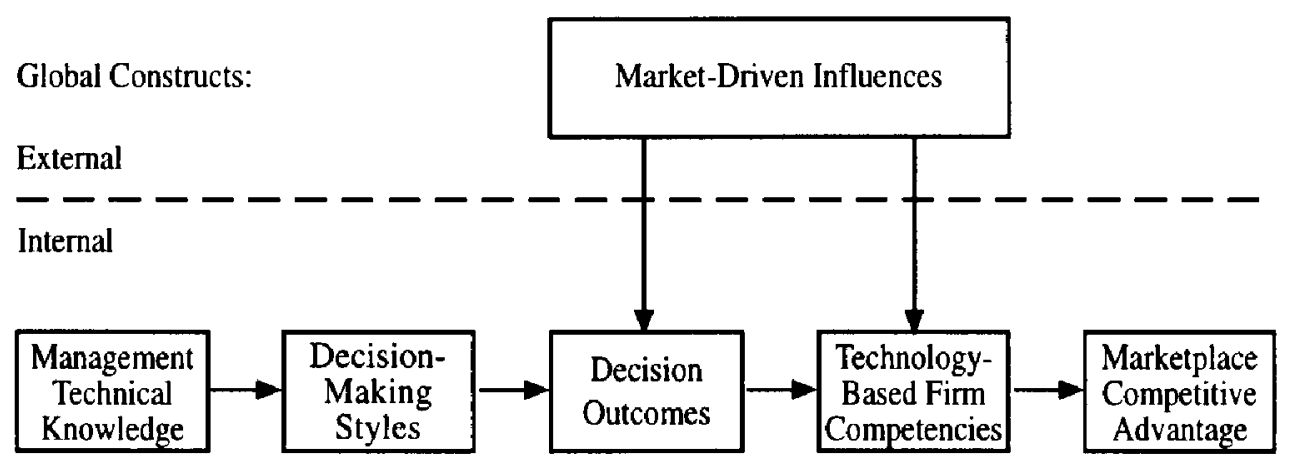

The linkages between effective technology management and competitive advantage (i.e., items 3 and 4 above) are discussed by Day (1994), and therefore will not be explicitly discussed. (Readers are referred to Day (1994) for a detailed discussion of these relationships). Since Day (1994) has established their linkage, we will build on this by investigating the necessary prerequisites for developing technology-based competencies. The nature of the relationships among technical 
knowledge, decision-making style, and decision outcomes will be discussed, identifying the underlying components of each construct in the model.

It should be noted that although the same model is presented in Figure 2, the critical difference is the level of analysis: Figure 2 shows a detailed, micro analysis as opposed to the macro level of analysis of Figure 1. For example, management technical knowledge in Figure 1 has three core variables: application, effects, and state of the-art technical knowledge. Figure 2 presents the variables used in the present study to operationalize the core constructs of management technical knowledge, decision making styles, and decision outcomes.

\section{Figure 2}

\section{A Micro Framework Linking Technical Knowledge and Competitive Advantage}

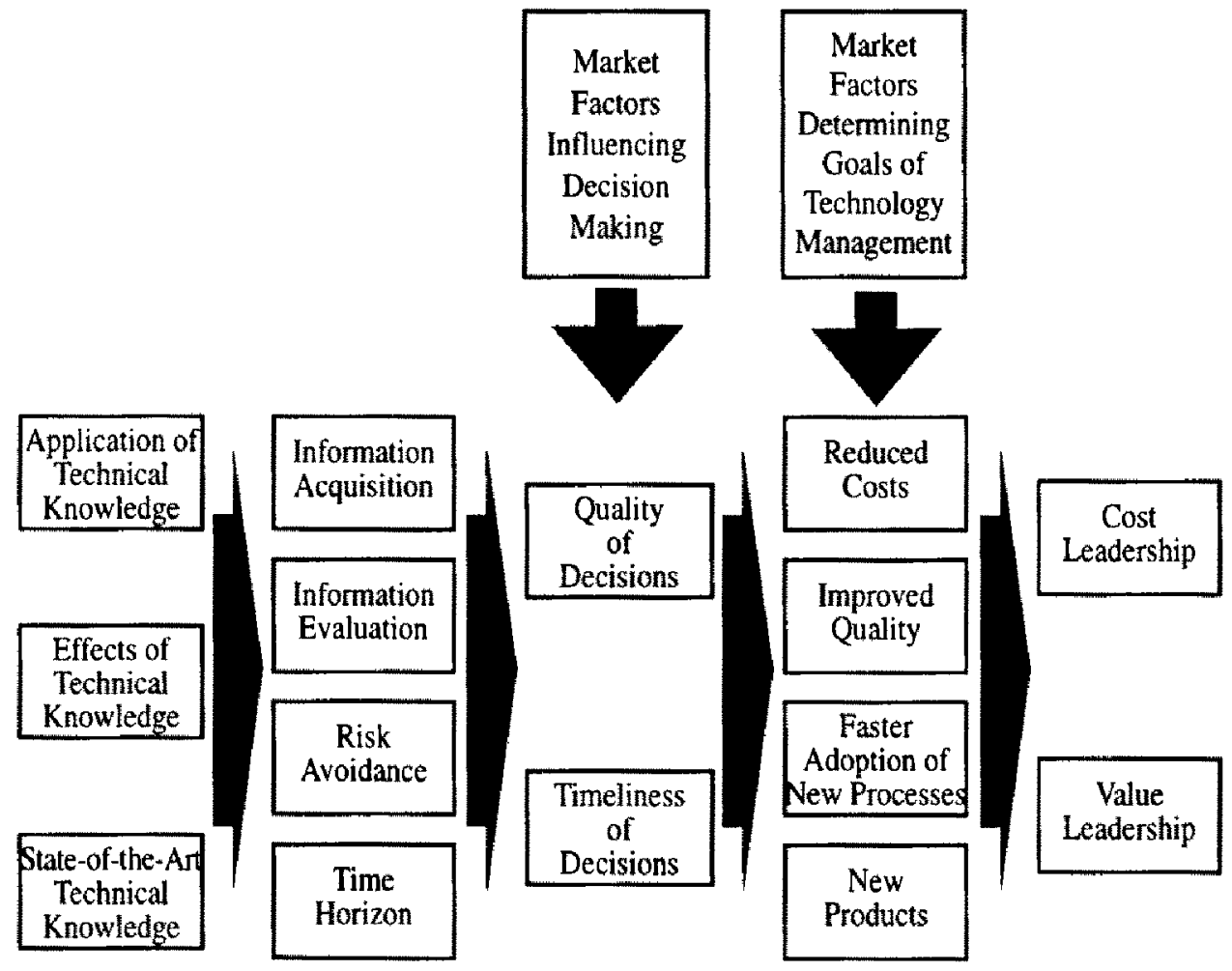

\section{Technical Knowledge, Decision-Making Style and Outcomes}

Johnson (1990) argues that technical knowledge is a prerequisite for improving the quality of technical decision making and concluded that to be more effective, technical decision making requires management to do several things. First, management should increase information use, both in terms of how much is considered (quantity) and how rigorously it is analyzed (thoroughness of analysis). 
Second, management must adopt a proactive approach to managing risk by learning how to deal with uncertainty. Third, management needs to make use of longer time horizons by avoiding situations that call for immediate decisions. A planning process can minimize the need for immediate decisions.

Decision-making style can be broken down into four dimensions: information acquisition, information evaluation, risk avoidance (how risk is perceived), and time horizon (when decisions are made) (Johnson, 1990). Information acquisition style reflects the degree to which a person will seek out information pertinent to the decision being made. It may involve soliciting opinions from others, asking questions, seeking out relevant studies, or relying on one's own understanding and knowledge. We contend that the amount of technical knowledge one possesses will be correlated with the information acquisition style used in gathering information. Managers with greater technical knowledge will be more likely to adopt an extensive search for information than managers with less technical knowledge.

First, greater amounts of technical knowledge broaden a manager's mind to the complexity of technical decisions and the plethora of available solutions, while managers with less technical knowledge may oversimplify the problem or seek to "satisfice" by adopting a less than optimal solution. Second, understanding breeds interest and excitement. Such an interest will lead to a more detailed approach to information acquisition. Third, the gathering of information is time consuming. Managers with less technical knowledge will be unable to adopt a very detailed approach to information acquisition. Managers with a greater amount of preexisting technical knowledge will be better able to assimilate and grasp the details of developing technologies than managers with less technical knowledge.

Hypothesis 1: The greater the technical knowledge of an operating manager, the more detailed his/her information acquisition style will be.

Information evaluation style may involve top down, bottom up, logical, intuitive, or systematic approaches, as well as what-if or scenario planning. It is believed that managers with a greater amount of technical knowledge will adopt a more systematic approach to decision making since a greater amount of information is available. Only through such a detailed process can information be accurately evaluated. Managers with less technical information must either adopt a detailed search to obtain the necessary information or rely on more intuitive methods of evaluation.

Hypothesis 2: The greater the technical knowledge of an operating manager, the more systematic (versus intuitive) his/her information evaluation style will be. 
The element of risk is an inherent condition of decision making. Managers often perceive different levels of risk given the same situation, which can be explained by a manager's previous experience, knowledge, information, and familiarity with a particular decision. Since risk is measured by the level of uncertainty, managers possessing greater expertise or knowledge tend to perceive lower levels of risk than less knowledgeable and less experienced managers in similar situations. Knowledge of the details of technological processes decrease the amount of risk perceived by the decision maker and are likely to be less risk averse than less qualified managers.

Hypothesis 3: The greater the technical knowledge of an operating manager, the less averse he/she will be to making manufacturing decisions under risk or uncertainty.

When making decisions, managers are confronted and influenced by time constraints. One such time constraint involves the lead time required to recoup the capital expenditures associated with a particular decision. For example, the decision to adopt new technology will likely require a large investment of capital. Due to the nature of major technological changes, large capital expenditures may be required over a prolonged period of time before any positive effects are realized. Making such a decision, although it may be in the best interest of the firm in the long term, may be financially devastating in the short term.

We argue that such decisions will be affected by the amount of technical knowledge possessed by the decision maker and that higher levels of technical knowledge result in the confidence necessary to invest in such long term projects. Managers with lower levels of technical knowledge will be more likely to adopt a short term perspective, since they lack the requisite knowledge to fully understand the new technology and opportunities for exploiting it.

Hypothesis 4: The greater the technical knowledge of an operating manager, the longer his/her time horizon will be in making manufacturing related decisions.

We evaluate the outcomes of the decisions along two dimensions: quality and timeliness of the decision. The quality of the decision can be judged by whether or not it was successful in accomplishing its goals. Greater levels of technical knowledge by management are expected to lead to better decision outcomes, assuming that the application of more effective decision-making styles will result in better decisions (i.e., higher quality decisions can be made in a more timely manner). Effective decision-making styles include detailed information acquisition, systematic information evaluation, less risk aversion, and a long-term perspective. Our reasoning is that managers with more relevant information will make better decisions than managers with less information, resulting in more 
successes. Since more information is understood, evaluated, and utilized, the resulting decision should be more successful.

Hypothesis 5: The greater the technical knowledge of an operating manager, the higher the quality of his/her manufacturing related decisions.

An age old maxim states that "More information is better than less." While this may be true, managers are bound by time in that there is an inherent trade-off between better quality decisions and time. Technical knowledge assists the manager in making timely decisions for several reasons. First, when a manager is familiar with the technical information, there is less need to gather additional information, since the manager's expertise serves as a first screen in evaluating options. Second, if additional information is necessary, he or she will be able to identify what type is needed. Managers with less technical knowledge must undertake an initial search to familiarize themselves with the new information. This allows technically competent managers the added advantage of making decisions in a more timely manner.

What might be a great decision at one point in time may not be nearly as attractive at another point in time. As less technically competent managers search for and study additional information, the opportunity to exploit a decision to its fullest may be missed, while technically competent managers already have the necessary information and can spend more time evaluating their options for the greatest probability for success.

Hypothesis 6: The greater the technical knowledge of an operating manager, the more timely (neither too early nor too late) his/her manufacturing related decisions.

\section{Methodology}

\section{Sample}

In order to test the theoretical model and the associated hypotheses a mail survey methodology was deemed most appropriate. The target population was comprised of two groups: top level manufacturing executives and operations managers (with day-to-day responsibility) of manufacturing firms. Both of these managers are of great interest to businesses since they play critical roles in determining manufacturing equipment- and services-related purchases. (See Hutt \& Speh (1995) for a presentation of the buying center construct and a description of buying center roles.)

Operation managers are the primary users of manufacturing or process technologies and are therefore likely to exert major influence over the buying decision process for technological (and technologically-related) purchases. In many 
cases operations managers are given the authority to be the ultimate deciders, personally making the final decision. Some operations managers also play gate-keeping roles if they have direct control over information used within the buying center. Therefore, operations managers should be viewed as a key constituency when it comes to making technology purchase decisions.

Likewise, top level managers are likely to exert a great deal of influence over the buying decision process, due to in large part to their position as strategy setters. Since technological purchases can have a dramatic impact on a firm's strategy, top-level mangers will want to insure that these purchases and the resulting technology "fit" with the organization's overall strategy.

To insure adequate representation of both top executives and operations managers in the sample, two mailing lists were compiled to sample the target population. To reach the top executives of manufacturing firms the first list was compiled utilizing information provided by the leaders of the American Production and Inventory Control Society (APICS) chapters from the Midwest. The leaders provided a list of senior executives that belonged to four APICS chapters. This list contained only names of high-level manufacturing executives from the midwestern United States. Therefore, the population of senior managers of manufacturing firms in the Midwest was surveyed. The second list, containing only operations managers, was obtained from the same four Midwest chapters of APICS. Each of the operations managers contained on this second list were included in the mail survey.

A total of 1,248 managers, including both operations managers and senior managers, were mailed questionnaires. A single follow-up survey was used in an attempt to obtain the largest number of possible respondents. A total of 169 usable questionnaires were returned, yielding a response rate of 13.5 percent. The response rate is representative for mail surveys not offering compensation (Hall, 1976; Ryan, 1987). Both operation managers and top management were represented in the final sample. Approximately $60 \%$ of the respondents were operating managers and $40 \%$ were top managers. A group comparison test was performed to determine whether there was any significant difference between operating and top managers across the variables in question. No significant differences were reported between the two samples on any of the variables. Therefore, the results of this study are equally comparable to operation managers and senior managers of manufacturing firms.

\section{Measurement}

All variables were measured using multiple items from a questionnaire using a 5-point Likert scale. The appendix contains a listing of the constructs used for all of the variables included in this study along with their associated reliability tests (Cronbach's alpha).

Technical Knowledge. Technical knowledge has received a great deal of attention in the operations literature as a theoretical concept, but has yet to be rigor- 
ously measured. This lack of attention may be attributable to the difficulty associated with operationalizing the concept of technical knowledge. Technical knowledge is defined as knowledge, information, and expertise in applying and managing technology that directly impacts the operations and manufacturing processes of the organization (Ghingold \& Johnson, 1997).

Drawing from the extant literature on the subject, three components or aspects of technical knowledge can be identified. (For a more detailed discussion please refer to Johnson (1990)). For the purposes of the present study, these components can be classified into the following three categories:

1. Application: Knowledge related to the application of equipment and process technologies by the manufacturing firm (Weitzel, 1984; Gregerman, 1981);

2. Effect: Knowledge related to the effect of equipment and process technology on the management of the manufacturing firm (Skinner, 1985);

3. Currency: Knowledge of state-of-the-art techniques or technologies gaining acceptance in advanced manufacturing firms (Thurow, 1987; Hayes \& Wheelwright, 1984; Henderson, 1982).

In order to measure technical knowledge, a variety of items representing each of these components were drawn from the extant operations literature (using five point interval scales). Results of reliability tests conducted on the questions used to measure each construct (Cronbach's Alpha) suggest that the questions, scales, and constructs were reliable measures of the concepts being investigated in the present study. The questions and scales used to measure technical knowledge demonstrated a high degree of inter-item reliability with Cronbach Alpha scores ranging from a low of .86 to a high of .94 . Technical knowledge was evaluated on the basis of knowledge scores for each of the three knowledge components independently. By treating the three components as different dimensions it was possible to determine if certain types of technical knowledge are more consequential than others.

Decision-Making Style. Decision-making style is a multidimensional construct that reflects a person's individual decision-making process. In particular, the four variables used are: information acquisition, information evaluation, risk (risk aversion), and time horizon (long-, short-term). Inter-item reliability was good with Cronbach Alpha scores ranging from .54 to .66 .

Decision Outcomes. Decision outcomes are evaluated by assessing the quality (success, failure) and timeliness (fast, slow) of the decision. Although there is an inherent trade-off between these two variables it is necessary to strike a balance between the two. Decisions that are evaluated as successful may have taken such a long time that the benefits were severely diminished, whereas a more timely, but less optimal decision may have resulted in a greater benefit to the organization. Cronbach alphas for the two decision outcome variables were .53 and .59 . 


\section{Statistical Analysis}

To test the relationships between technical knowledge (application, effect, currency), and decision-making style (information acquisition, information evaluation, risk avoidance, time horizon), and decision outcome (quality and timeliness of decisions) a series of multiple regression analyses were performed to determine how well respondents' technical knowledge scores could predict the decision style used and decision outcomes. Since all of the variables were obtained using a Likert 5-point scale, which approximated an interval scale, we used multiple regression analysis, making it possible to treat the data as continuous measures of technical knowledge, decision making, and outcomes. This allows for a more rigorous test of the hypotheses. Therefore, each of the dimensions of decision-making style and outcomes was introduced as dependent variables, while the three dimensions of technical knowledge were used as independent variables. The general model used in the regression analysis can be represented as follows:

Decision-Making Style and Outcomes $=f($ technical knowledge $)$

The specific models tested included a total of six multiple regression models.

Information acquisition $=$

$B_{1}$ Knowledge Application $+B_{2}$ Knowledge Effect $+B_{3}$ Knowledge Currency

Information evaluation $=$

$B_{1}$ Knowledge Application $+B_{2}$ Knowledge Effect $+B_{3}$ Knowledge Currency

Risk Aversion $=$

$B_{1}$ Knowledge Application $+B_{2}$ Knowledge Effect $+B_{3}$ Knowledge Currency

Time Horizon, $=$

$B_{1}$ Knowledge Application $+B_{2}$ Knowledge Effect $+B_{3}$ Knowledge Currency

Quality of Outcome $=$

$B_{1}$ Knowledge Application $+B_{2}$ Knowledge Effect $+B_{3}$ Knowledge Currency

Timing of Decision $=$

$B_{1}$ Knowledge Application $+B_{2}$ Knowledge Effect $+B_{3}$ Knowledge Currency

The results of the regression analyses appear in Table 1. 


\section{Table 1}

\section{Regression Analysis of Decision Making Variables}

Technical Knowledge Components

\begin{tabular}{|c|c|c|c|c|c|}
\hline $\begin{array}{l}\text { Decision-Making } \\
\text { Variables }\end{array}$ & $\begin{array}{l}\text { Application of } \\
\text { Technical } \\
\text { Knowledge } \\
\text { Beta Weight } \\
\text { (t) }\end{array}$ & $\begin{array}{c}\text { Effects of } \\
\text { Technical } \\
\text { Knowledge } \\
\text { Beta Weight } \\
\text { (t) }\end{array}$ & $\begin{array}{l}\text { Currency of } \\
\text { Technical } \\
\text { Knowledge } \\
\text { Beta Weight) } \\
\text { (t) }\end{array}$ & $\mathrm{R}^{2}$ & $F$ \\
\hline $\begin{array}{l}\text { Information } \\
\text { Acquisition }\end{array}$ & $\begin{array}{r}.355 \\
(3.10)^{3}\end{array}$ & $\begin{array}{r}-.028 \\
(0.32)\end{array}$ & $\begin{array}{c}.181 \\
(1.95)^{4}\end{array}$ & .13 & $6.92^{2}$ \\
\hline $\begin{array}{l}\text { Information } \\
\text { Evaluation }\end{array}$ & $\begin{array}{r}.154 \\
(1.61)\end{array}$ & $\begin{array}{r}.081 \\
(1.15)\end{array}$ & $\begin{array}{c}.151 \\
(1.98)^{4}\end{array}$ & .10 & $5.48^{2}$ \\
\hline Risk Handling & $\begin{array}{r}.337 \\
(3.84)^{2}\end{array}$ & $\begin{array}{r}.031 \\
(0.49)\end{array}$ & $\begin{array}{c}0.80 \\
(1.14)\end{array}$ & .16 & $9.40^{1}$ \\
\hline Time Horizon & $\begin{array}{r}.533 \\
(5.30)^{\prime}\end{array}$ & $\begin{array}{r}.028 \\
(0.38)\end{array}$ & $\begin{array}{c}.211 \\
(2.63)^{3}\end{array}$ & .30 & $20.49^{1}$ \\
\hline Quality & $\begin{array}{r}.312 \\
(3.50)^{2}\end{array}$ & $\begin{array}{r}.009 \\
(0.14)\end{array}$ & $\begin{array}{r}.158 \\
(2.25)^{4}\end{array}$ & .17 & $10.10^{1}$ \\
\hline Timeliness & $\begin{array}{r}.393 \\
(3.47)^{2}\end{array}$ & $\begin{array}{r}.104 \\
(1.26)\end{array}$ & $\begin{array}{r}-.026 \\
(0.29)\end{array}$ & .13 & $7.46^{1}$ \\
\hline
\end{tabular}

${ }^{1}$ Test statistic significant at $<=0.0001$

${ }^{2}$ Test statistic significant at $<=0.001$

${ }^{3}$ Test statistic significant at $<=0.01$

${ }^{4}$ Test statistic significant at $<=0.05$

\section{Results and Discussion}

The results suggest that technical knowledge is a very strong predictor of the decision-making style and outcome variables investigated in the present study. All models reported high levels of statistical significance ( $p<.001$ ), with $R^{2}$ s ranging from a low of .10 to a high of . 30 . Such results support the argument that technical knowledge does in fact influence the decision-making styles of managers. Findings also reflect that technical knowledge will have a positive influence on the quality and timeliness of decision making.

Of the three technical knowledge components studied, application and currency (or state-of-the-art technological innovations) were the strongest predictors of the 
decision-making variables, thereby confirming hypothesis $\mathrm{H}_{1}$. Technical knowledge on how to apply equipment and process technologies was the strongest predictor of decision-making style, reaching significance in five of the six models tested. These findings suggest that the amount of technical knowledge possessed by managers will have a large effect on the decision-making style used and the success of subsequent outcomes. Managers with higher levels of technical knowledge are more likely to be willing to assume greater levels of risk, adopt longer-term perspectives, and utilize more intensive information-gathering techniques.

The outcomes of the decisions that are made by managers with higher levels of technical knowledge are also more likely to be successful in terms of the quality of the outcome and the timeliness in which the decision was made. These findings provide support for hypotheses $\mathrm{H}_{5}$ and $\mathrm{H}_{6}$. Due to the larger amount of technical knowledge available to these managers, they are capable of determining what additional information is needed, where to get it, and are able to get it sooner than the managers with less knowledge. Such a situation affords a firm the opportunity to move more quickly and decisively in capturing and exploiting a competitive advantage.

The other dimension of technical knowledge that was important in predicting the decision-making style was currency. Currency was significant $(p<.05)$ in explaining decision making style and outcomes in four of the six models. Managers that keep themselves up to date on the most recent technologies and techniques available tend to use extensive techniques in gathering and evaluating information, and make decisions with longer time horizons than managers with less knowledge of current developments, and make higher quality decisions.

It should be noted that the third element of technical knowledge, effect of equipment and technology on management, was not significant in any of the models tested (rejecting hypothesis $\mathrm{H}_{2}$ ). It is possible that technical decisions do not currently consider the effects of technological decisions on management because they have been considered irrelevant in the past. The results may also be a function of the type of people making the technical decisions within the firm. Being largely engineering or scientifically trained in their professions, managerially related issues associated with technical decisions may not be within their area of training.

Therefore, it is not that these effects are unimportant to the firm as a whole, but that the training and expertise of the managers making the decisions are incongruent with managerial implications. For a long time such "technical" decisions have been left to the technocrats of the organization, with little if any consideration for the effects on management. Another explanation for the lack of significance is that application and effect may be inseparable within the decisionmaking process.

This aside, the findings of the study are generally consistent with the proposed theoretical model and research hypotheses. The results offer preliminary empirical evidence establishing the value of technical knowledge as an important 
resource for manufacturing firms, particularly as a means for achieving and sustaining a competitive advantage (Barney, 1991).

However, it should be noted that the three components of technical knowledge were not equal predictors of the decision-making variables (see Table 1). In particular, knowledge related to the application of technology was the strongest predictor, while knowledge related to the managerial effects of technology was the weakest predictor. Knowledge of state-of-the-art techniques and technologies was a significant predictor for all of the decision-making variables except risk aversion and timeliness.

Overall, managers with higher levels of technical knowledge employ more advantageous decision-making styles, in terms of the four dimensions studied, and have more favorable decision-making outcomes. These results highlight the importance of technical knowledge to a firm that is striving to establish and maintain a competitive advantage.

\section{Implications}

\section{For Management of Technical Knowledge}

Viewing technical knowledge as a strategic asset upon which to build a competitive advantage used to be considered an unorthodox view for most management professionals. However, with the popularity of the resource-based view of the firm (Wernerfelt, 1984; Barney, 1991) and its implications for exploiting the use of information in establishing a competitive advantage, the importance of having more knowledge cannot be ignored. The importance of knowledge as a resource may well be the next great development in the ever expanding search for competitive advantage.

Given the rapid pace of technological change occurring throughout the world, the demand for timely and accurate decisions simply cannot be postponed without dire consequences. Decisions pertaining to when to adopt new technologies and how to fully exploit them become imperative if a firm is going to succeed. Therefore, managers must take appropriate actions to insure the future viability of their organizations on technological grounds. Several things are clear: (1) The technical component of the organization's resources is not a generic product, but one that must be actively managed to be successful, (2) The implementation of technical decisions can offer firms a competitive advantage that cannot be easily imitated by competitors, since the requisite knowledge, skills and training are imbedded in the human resources of the firm, and (3) Greater amounts of technical knowledge will result in higher quality and more timely decisions.

All too often, managers see themselves as repositories for endless information and targets for incessant communications. This clutter and competition for the manager's time and attention has had a negative outcome. Many managers are unreceptive to new information whether from vendors or other sources. Knowledge, and of particular importance to the present study, technical knowledge, is a 
resource with major strategic ramifications that will impact a firm's level of competitiveness.

The acquisition and development of technical knowledge will have longterm implications for business organizations, since managers with more technical knowledge tend to adopt a long-term perspective when it comes to making decisions. Managers must be trained to view such information not as an intrusion into their "normal" role as manager, but as valuable information that can have a great impact on an organization's performance. In addition, it can be argued that such information should be actively sought out and viewed as opportunities, and not as threats to their time. Managers who recognize the value of additional technical knowledge will be able to exploit opportunities that may otherwise have gone unnoticed. This change in the mind-set of many managers will be required before specific "knowledge strategies and tactics" can be implemented.

The starting point in this process rests with top management. Changing management values, orientations or cultures is difficult. Organizational inertia, resistance, conservatism and fear all limit a firm's ability to change and adopt new and more effective methods of operation. A shift in the organizational culture to embrace technical knowledge as a vehicle for long-term competitive advantage must first be adopted by senior management. This top down approach is necessary to develop an organizational commitment to, and ultimately a written policy for, knowledge acquisition that reassures all levels of management that the time taken to gain technical knowledge is time well spent. The support of top management is the catalyst in establishing an atmosphere in which technical knowledge is valued and pursued.

\section{For Procurement}

Once the value of technical knowledge as a resource is accepted, purchasing and materials management professionals can play important roles for their organizations. Burt (1984) has called for purchasing managers to accept their important role as a key contributor in the strategic management of the firm. Purchasing managers must recognize the value of knowledge in today's competitive marketplace and take specific steps to acquire the necessary information, establish distinctive competencies, and build long lasting competitive positions.

In order to develop a competitive advantage, purchasing managers can develop specific strategies for managing the process of knowledge procurement within their firms. One approach could involve what may be called "no dollar cost" sources of technical knowledge or proactive gate-keeping. These strategies involve basically no additional costs and may include such things as:

1. Certifying or qualifying strategic vendors and developing strategic relationships with technological leaders. Inclusion of vendors that provide strategically important materials in the decision-making process can increase the organization's amount of technical knowledge. 
2. Welcoming or encouraging sales calls and presentations, particularly those of a technical nature. Recognizing the importance of technically knowledgeable managers that are more willing to entertain new technological innovations by soliciting the assistance of firms with superior technical information.

3. Increasing or maximizing technical inputs and information from all current and potential suppliers to benefit from their specialized knowledge and competencies. Adopting an open door policy with regard to technical knowledge will allow for a relationship more conducive to learning.

4. Encouraging technical personnel to interact with technical vendors and technical experts from vendors. Staying abreast of technological trends will increase a firm's ability to identify potentially useful innovations before competitors. The additional lead time allows firms to develop first mover advantages that cannot be easily imitated.

Such proactive approaches to procuring and disseminating technical knowledge involve non-monetary costs and the desire to search out relevant information and integrate it into the organization. It should be noted that these strategies do require a new approach to managing knowledge as a resource. Therefore, significant incremental effort and specific strategies are required to successfully utilize the technical knowledge gathered.

Purchasing efforts regarding the gathering of technical knowledge may also require the disbursement of additional capital. These additional funds can be used for the proactive procurement of technical knowledge. Although there are a variety of different sources that can provide technical knowledge to a firm and its managers, some of the more commonly used sources include workshops or seminars, consulting contracts with individuals or organizations possessing valuable expert knowledge that can benefit the firm and its operating personnel, subscriptions to relevant technical and professional journals and periodicals which can be passed on for reading by operations managers, trade show attendance (including multiple trade shows, not just the firm's industry show), and company support for the continuing education of operating personnel.

It can be said that many firms currently "buy" one or more of these sources of technical knowledge. However, that does not insure that the firm will gain the technical knowledge required to be successful. Although the information is available, the problem is the lack of coordination between the acquisition of knowledge and its implementation. All too often, firms buy such information without a long-term knowledge procurement strategy in place. Clearly the impact of informed, cutting edge, long-term oriented decision making on firm competitiveness is great. It is imperative that all levels of management be valued for the important role they play in developing the kinds of policies and culture that encourage the transfer of technical knowledge among the managers of the firm. 


\section{For Management}

Competitive advantage lies at the heart of strategic management, so any discussion of competitive advantage will have implications for management. Studying the linkage between customers, their needs and expectations, and the firm's actual product offering is the basis for developing a competitive advantage. In this paper we have discussed one potential source upon which a competitive advantage can be built: technical knowledge. By increasing the quantity of technical knowledge within a firm, managers can expect to recognize improvements in the quality and timeliness of decision making in matters pertaining to technological processes within the firm. Educating themselves and their employees on technical processes and information opens the door to more productive decision making.

Although the present study focused on technical knowledge as a means of developing a competitive advantage, it should not be viewed in isolation from the rest of the organization's resources and activities. Instead, technical knowledge should be viewed as an example of how information resources can be utilized in establishing a competitive advantage. Although there are a variety of information resources available to firms, we chose technical knowledge to illustrate the point that information and knowledge can be resources upon which a competitive advantage can be built. The development of a sustainable competitive advantage is a complicated undertaking and all of the components of an organization must work together to be successful. However, the availability of technical knowledge within an organization will affect the firm's performance. The usage of this technical knowledge will assist managers in exploiting technological synergies and efficiencies. Adequate amounts of technical knowledge will provide the foundation for the ultimate survival of the firm.

As an example of the unavoidable interrelatedness among departments, Wilson \& Ghingold (1987) noted that frequently there have been poor coordination and communication between R\&D and marketing departments. The production side of many business organizations is not adequately linked to the needs of the marketplace. Marketing may need to take a more active role in specifying technical advancements currently under development since they possess the requisite knowledge of consumer desires. In this way customers will ultimately be more satisfied with the products developed by the firm, thereby helping the firm establish a potential competitive advantage.

In the context of this paper, management has again several roles to play. For example, management should be actively involved in technological issues affecting manufacturing to insure that any such investments do in fact contribute to making the organization more competitive (i.e., developing or sustaining a competitive advantage). Manufacturing technology decisions that do not meet this basic threshold should be challenged. Understanding the technical issues and how they will affect the organization is key to making the best decision possible. Managers that stay abreast of the latest technological advancements will be in a better 
position to make these critical decisions in a timely and efficient manner. Since the managers are current in technological matters they will more accurately assess the potential impact of any changes on the future performance of the firm.

Management also has the responsibility for guiding manufacturing technology by highlighting the areas most in need of attention. In order for managers to accurately assess such situations, it is important that they have the necessary technical knowledge to make educated decisions. For example, management should indicate whether cost leadership is the desired goal versus quality or feature enhancement (differentiation). The strategy chosen by management will indicate the path and pattern of resource allocations that will be most beneficial to achieving a sustainable competitive advantage. Depending on the strategy chosen, manufacturing and engineering and all other functions will choose different paths in order to reach the goals that have been set. A solid understanding of the competitive advantage being sought is necessary to make strategic decisions that are consistent with the firm's overall strategy.

A third management issue involves the marketing and communicating of technical skills and achievements. This problem can be looked at in several ways. If proper management of technology has yielded an advantage, management will be responsible for exploiting it. Thus, management must plan for the introduction of "new and improved" product offerings that will maximize the competitive advantage. This mandates target marketing to identify and reach appropriate prospects who will value the new offering. Additionally, management may seek to exploit the firm's technical competence as a competitive tool, offering it as a value-added service to both current and prospective customers. The use of technical competence as a value-added service has its own set of management and programming requirements.

\section{Conclusions}

This paper has promoted a new proposition for management's consideration. A theoretical model was developed based on the concept of knowledge, particularly technical knowledge, as it is related to manufacturing operations and processes, which highlights the importance of knowledge as a strategic resource. The foundation of the model is that a firm's technical knowledge can be a valuable resource in helping firms build or maintain a competitive advantage.

Results of an exploratory study examining the relationship between technical knowledge and operations decision making demonstrated a strong linkage between managers' technical knowledge and effectiveness of decision making. Our results suggest that firms with managers that have more technical knowledge tend to make higher quality and more timely decisions. Such results are consistent with the proposition that technical knowledge cannot be ignored. Therefore, the extent to which technical knowledge is acquired, stored, disseminated and utilized will be an important determinant of a firm's long-term competitiveness. 
Top management has the preeminent role to play in this process. It is through the actions of senior managers that an organization and its management can develop a new culture where technical knowledge is valued and pursued. Only then will purchasing management have important responsibilities in this context. Proactive strategic purchasing adds new priorities to its management: developing strategic knowledge sources and effectively managing knowledge procurement. Similarly, managerial implications for management were developed.

Management's involvement here is to link technical decision making with the strategic goal of developing and sustaining competitive advantage, identifying the appropriate technical objectives, and developing effective strategic programs to exploit technically-based advantages. Perhaps the most critical issue for all fields and levels of management, however, is to recognize the importance of technical knowledge and its impact as one of the crucial "inputs" needed for a firm's success in a dynamic and highly competitive global marketplace.

Specifically, organizations must be conscious of the effect of management's technical competency on future performance. By understanding the results of the present study management can focus their attention on increasing the quantity and quality of technical competence within its organization. The relationships discovered suggest that managers need to devote considerable time to the development of technical expertise. Such expertise can have a dramatic influence on the decision-making style of managers. The impact of technical training programs becomes a prime avenue for enhancing a firm's effectiveness by altering the decision-making style of its managers. Firms that pursue technical training for its managers will benefit from increases in information acquisition and evaluation, risk handling, longer time horizons, better quality decisions, and decisiveness in decision making.

\section{References}

Amit, R., \& Schoemaker, P.J.H. (1993). Strategic assets and organizational rent. Strategic Management Journal, 14, 33-46.

Barney, J. (1991). Firm resources and sustained competitive advantage. Journal of Management. 17, 99-120.

Bartness, A., \& Cerny, K. (1993). Building competitive advantage through a global network of capabilities. California Management Review, 36(1), 78-103.

Becker, G.S. (1964). Human capital. New York: National Bureau of Economic Research.

Burt, D.N. (1984). Proactive procurement. Englewood Cliffs, NJ: Prentice-Hall.

Day, G.S. (1994). The capabilities of market driven organizations. Journal of Marketing, $58,37-52$. 
Day, G.S., \& Wensley, R. (1988). Assessing advantage: A framework for diagnosing competitive superiority. Journal of Marketing. 52, 1-20.

Ghingold, M., \& Johnson, B. (1997). Technical knowledge as value added in business markets: Implications for procurement and marketing, Industrial Marketing Management, 26(3), 271-280.

Gregerman, I.B. (1981). Knowledge worker productivity. American Management Association, AMA Briefing.

Hall, J.L. (1976). Organizational technology and executive succession. California Management Review, 19(1), 35-39.

Hayes, R.H., \& Wheelwright, S.C. (1984). Restoring our competitive edge: Competing through manufacturing. New York: John Wiley \& Sons.

Henderson, R.P. (1982). The high technology industry is taking off. But there may be one hitch: The serious shortage of engineers. How did it happen and what should be done? Enterprise, March.

Hill, C.W. (1988). Differentiation versus low cost or differentiation and low cost: A contingency framework. Academy of Management Review. 13, 401-412.

Hutt, M.D., \& Speh, T.W. (1995). Business Marketing Management.(5th ed.). Dryden.

Johnson, B. (1990). The interaction of equipment and process technology knowledge and decision making methodology. Unpublished doctoral dissertation, University of Cincinnati, Cincinnati.

Leonard-Barton, D. (1992). Core capabilities and core rigidities: A paradox in managing new product development. Strategic Management Journal. 13 (Summer), 111-125.

Mahoney, J.T., \& Pandian, J.R. (1992). The resource-based view within the conversation of strategic management. Strategic Management Journal, 13, 363-380.

McFarlan, F.W., McKenney, J.L., \& Pyburn, P.P. (1983). Information archipelago-plotting a course. Harvard Business Review, 16 (January-February), 145-156.

Nayak, P.R. (1984). Too many U.S. technologists are managerially illiterate. $\underline{\text { High Tech- }}$ nology, September, p. 10.

Penrose, E.T. (1959). The theory of the growth of firms. New York: John Wiley \& Sons.

Peteraf, M.A. (1993). The cornerstones of competitive advantage: A resource-based view. Strategic Management Journal, 14, 179-191.

Porter, M.E. (1980). Competitive strategy. New York: The Free Press. 
Porter, M.E. (1985). Competitive advantage: Creating and sustaining superior performance. New York: The Free Press.

Raho, L.E., Belohlav, J.A., \& Fiedler, K.D. (1987). Assimilating new technology into the organization: An assessment of McFarlan \& McKenney's model. Management Information Systems Quarterly, 11, 47-57.

Ryan, M. (1987). The influence of technologists on corporate decision-making in the United Kingdom. International Journal of Operations Management. 7(3), 14-25.

Schmenner, R.W. (1983). Every factory has a life cycle. Harvard Business Review, 16, (March-April), 121-129.

Skinner, W. (1985). Manufacturing: The formidable competitive weapon. New York: John Wiley \& Sons.

Teece, D.J., Pisano, G., \& Shuen, A. (1991). Dynamic capabilities and strategic management. working paper, University of California, Berkeley.

Thurow, L.C. (1987). The task at hand: After decades of excuses, it's time for American managers to learn technology. The Wall Street Journal, (June 12), 46d.

Tomer, J.F. (1987). Organizational capital: The path to higher productivity and well-being. New York: Praeger.

Weitzel, J.R. (1984). Managing the implementation of information systems: A multiple industrv investigation of process. information systems-user relationships, and project outcomes. Unpublished doctoral dissertation, University of Cincinnati, Cincinnati.

Wernerfelt, B. (1984). A resource-based view of the firm. Strategic Management Journal. 5, $171-180$.

Williamson, O.E. (1975), Markets and hierarchies: Analysis and antitrust implications. New York: Free Press.

Wilson, D.T., \& Ghingold, M. (1987). Linking R\&D to market needs. Industrial Marketing Management. 16(3), 207-214. 


\section{Appendix}

Reliability tests (Cronbach Alphas) for all constructs used in the study.

Technical Knowledge

Application of Technical Knowledge $\quad .94$

Effects of Technical Knowledge $\quad .94$

State-of-the-Art Technology Knowledge $\quad .86$

Decision-Making Styles

Information Acquisition $\quad .58$

Information Evaluation $\quad .61$

Risk Avoidance $\quad .54$

Time Horizon $\quad .66$

\section{Decision Outcomes}

Quality of Decisions

Timeliness of Decisions 